JSTサービス紹介

)) From JST Product Portfolios

\title{
「JDream II」のご紹介
}

\section{JST 情報提供部 普及企画課 加藤 治 ; 山下昌二}

\section{1. 概要}

平成18年4月より「JDream II」の本格的サービス が開始された。

JSTでは科学技術文献データベースサービスとし て,「JOIS」を昭和51年10月にサービスを開始し， $\lceil\mathrm{JDream} 」$ を平成15年10月に主に大学や病院等の利 用者向けにサービスを開始した。JDream IIはこれ らの2つのサービスを統合し, 飛躍的に機能を向上 させた新しい文献検索サービスである。

JSTは国内外の科学技術文献と国内の医学関連文 献を収集し, 概要 (抄録) の作成, キーワードの 付与等の加工を行っている。これまでに収録して きた記事数は 3,800 万件を超え, 利用件数（検索件
数）は年間 4,000 万件以上となっている。

\section{JDream IIを使う理由}

最近はインターネット上の一般的な検索エンジ ン（Yahoo!®やGoogle ${ }^{\mathrm{TM}}$ など）で情報を得ることが できるが, その検索結果には不確かな情報, 信頼性 の低い情報も含まれている。JDream IIの情報源は科 学技術に関する学術雑誌や専門誌, 公共資料に限ら れており, 出典がはっきりしているため, 信頼性の 高い情報を得ることができる。また, 外国文献で あっても, 日本語で記事内容をまとめた概要（抄 録）を付けているので, 多くの情報の中から必要な ものを素早く見つける時にはとても便利である。

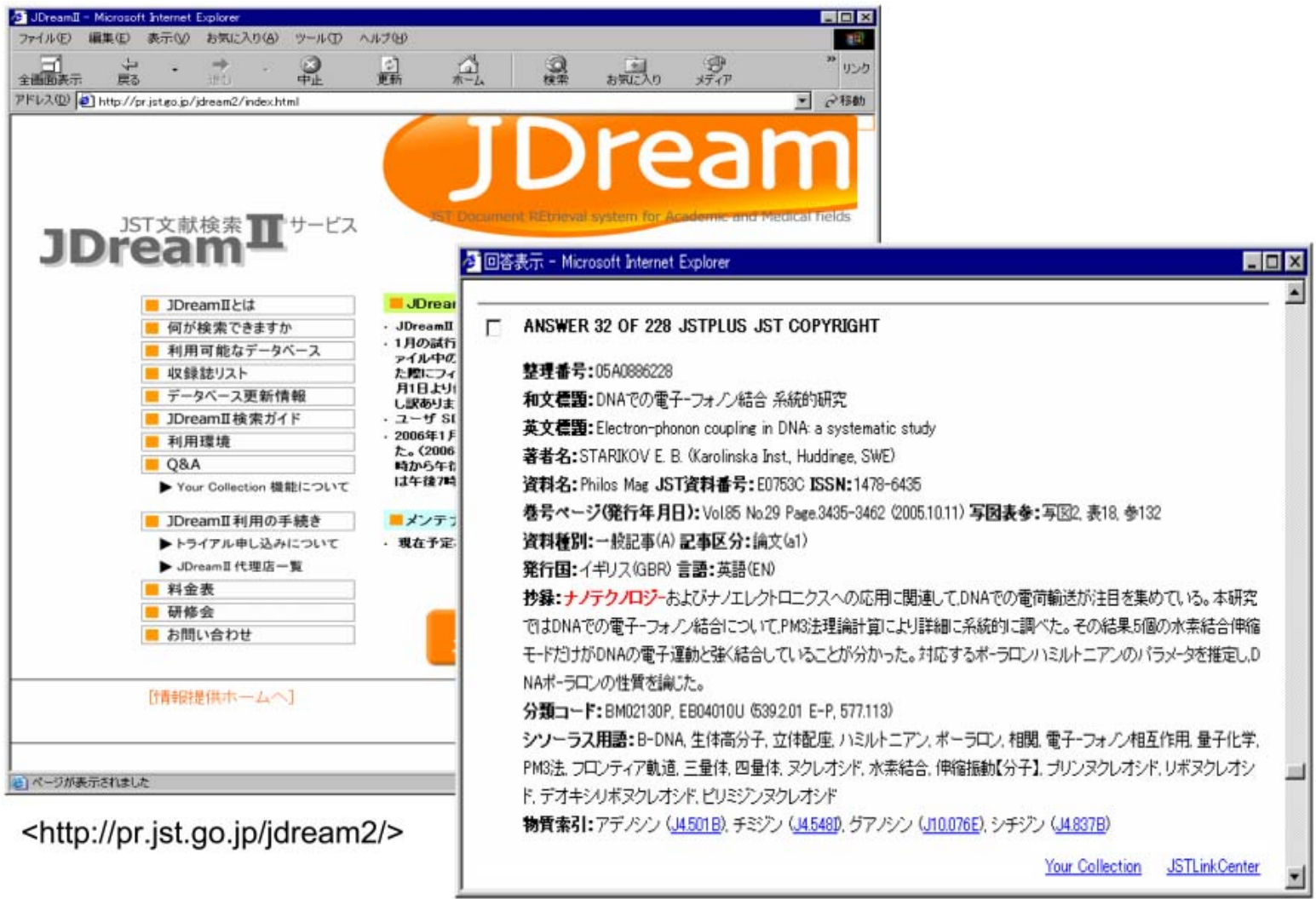

図1 JDream II<トップページ>と詳細情報 


\section{JDream ॥の特長}

JDream IIの特長は以下のとおりである。

(1) JDream IIで提供している複数のファイルに刘 して同時に検索が可能なマルチファイル検索に対 応している（図2）。

(2) JDream IIからJ-STAGEや医学・薬学予稿集全 文データベース(図3)をはじめ,原文献(電子ジャー ナル）へのリンクやコピーサービスへの連携が充 実している。

(3) きめの細かい高度な検索が可能な「コマンド
モード (図4)」と, 簡単な操作で検索が可能な「シ ンプルモード（図5）」を用意。どちらのモードも 全文検索エンジンを採用している。

（4）利用者が登録したテーマに基づき, 最新情報 の定期配信型サービス（SDIサービス）を提供して いる。

(5) 利用者が自由に入力したキーワードから同義 語を案内するJSTシソーラスブラウザを搭載。これ により初心者でも網羅的な検索を行うことが可能 である（図6）。

図2 マルチファイル検索

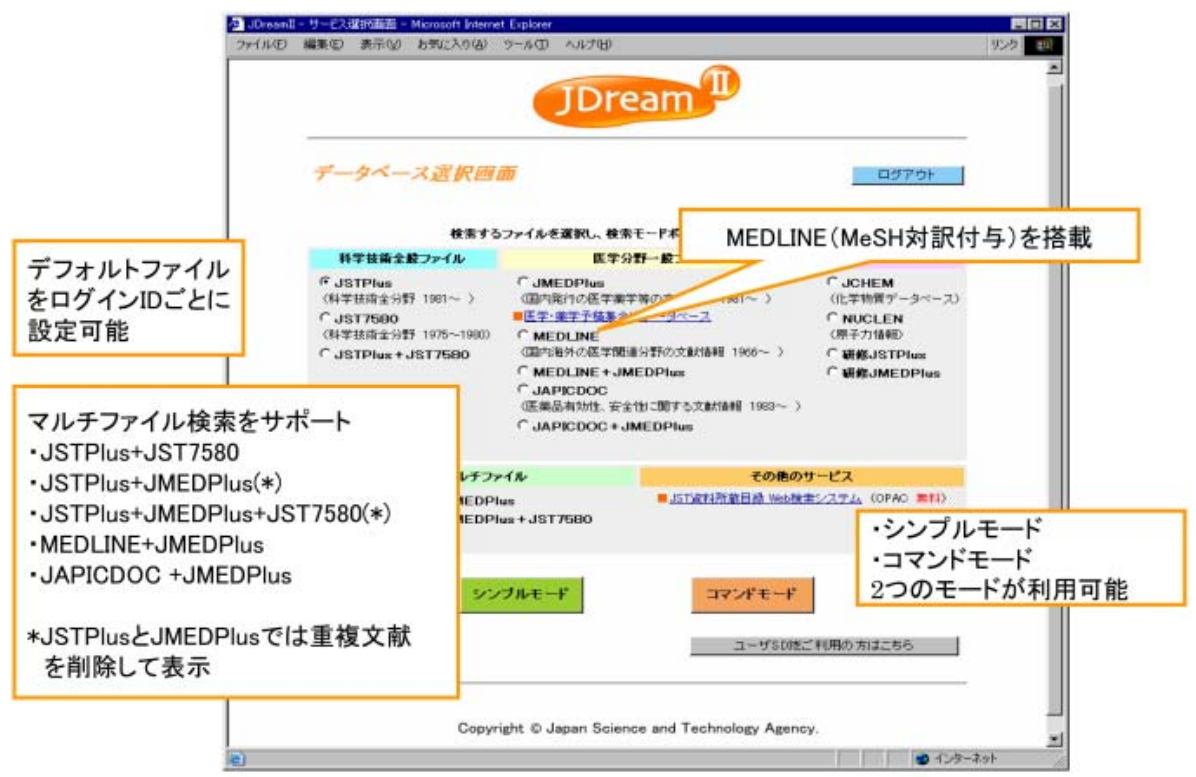

図3原文献ヘのリンク

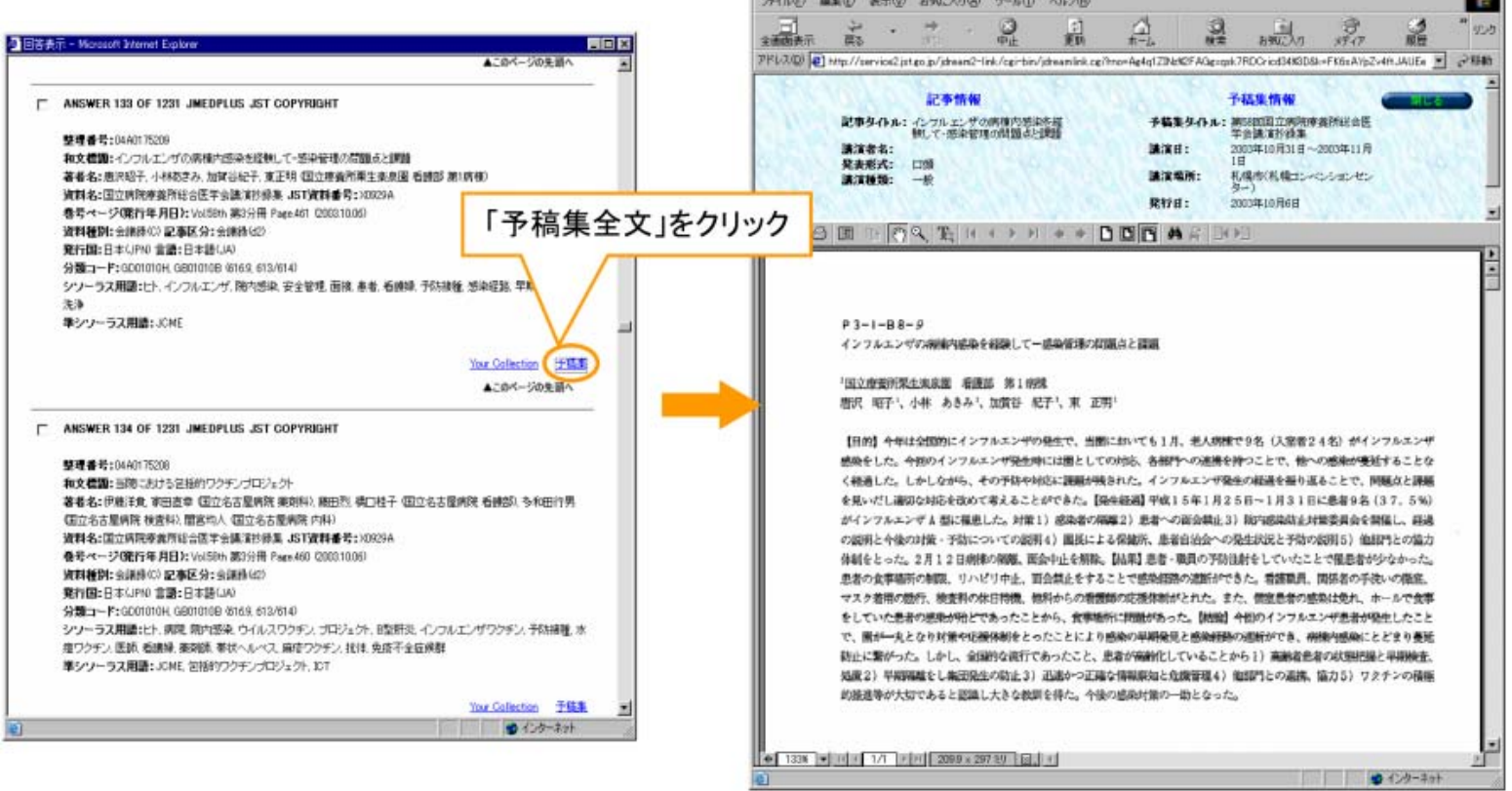




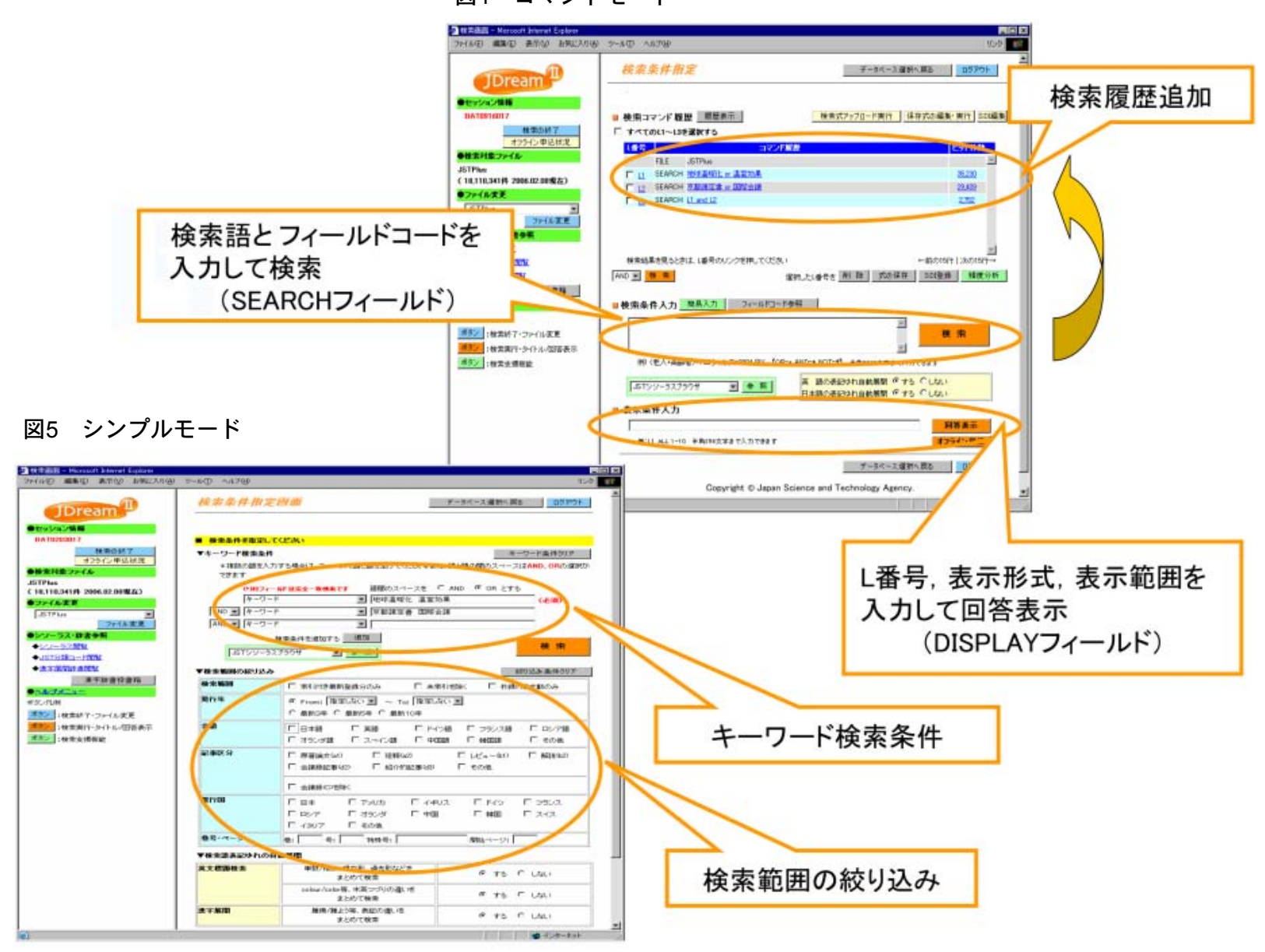

図6 JSTシソーラスブラウザ

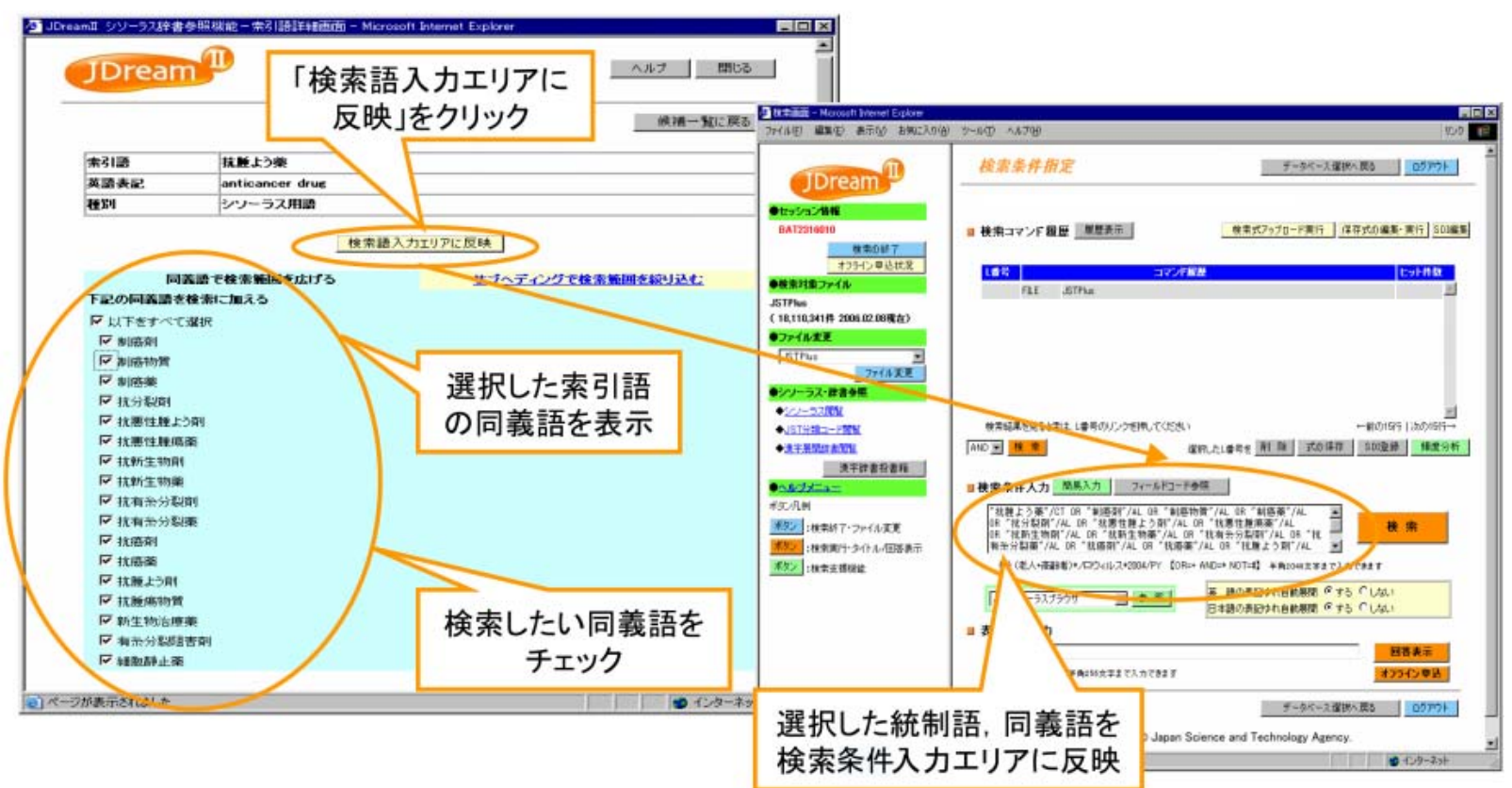




\section{JDream ॥の活用}

JDream IIの利用により，以下のような既存技術 の掌握による研究開発の効率化やコスト削減に貢 献できると考えている。

\section{(1) 技術動向等の把握}

効率的な研究開発を行うためには, 他の企業や 大学等の研究動向や技術動向を的確に把握するこ とが必須である。

JDream IIのデータベースには既に説明したとお り, 多岐にわたる国内外の科学技術文献情報が収 録されており, JDream IIで検索した結果をさまざ まな切り口で分析することにより, 研究開発の効 率化等に資することができる。

例えば, JDream IIは, 検索結果である複数の文 献を分析し「どの機関（またはどの研究者）が論 文を発表しているか」等の頻度分析を行う機能を 搭載している（図7）。こうした分析機能を使用す ることにより, 昨今注目されている産学連携とし ての連携先機関等の探索にも活用できる。これら の頻度分析機能は無料で行えることが特長である。

平成18年4月時点では頻度分析機能の搭載のみで あるが, 将来的には分析機能を強化し, 結果をビ ジュアルに表示するような機能も検討を進めてい る。

\section{(2) 先行技術調査への活用}

先行技術調査が不十分として異議申し立てされ るケースのうち, 約 3 割が非特許文献によるもので ある。先行技術の調査というと, 一般的には, 特 許情報の調査を思い浮かべるが, 実際は科学技術 文献の調査も非常に重要であり, 操作性が高い JDream IIを利用することで, 先行技術調査の精度 を大幅に向上できる可能性がある。

\section{5. 多様な料金制度}

昨今の研究者・技術者等のエンドユーザ等の利 用の拡大を考慮し, 年間固定料金の契約制度も用 意した。お客さまの使い方によっては，従来どお り, 従量料金契約を選ぶこともでき, 契約の選択 肢が広がったと言える。また, 各種オプション契 約も用意している。

\section{6. 今後について}

JDream IIでは, その開発に当たって,「お客さま のニーズを徹底的にお伺いし, いわばお客さまに 作っていただく」という姿勢で取り組んできた。 今後も皆さまからのご意見, ご要望について, JDream IIのシステム改良および運営等に反映でき るよう, 最大限の努力をしていく所存である。

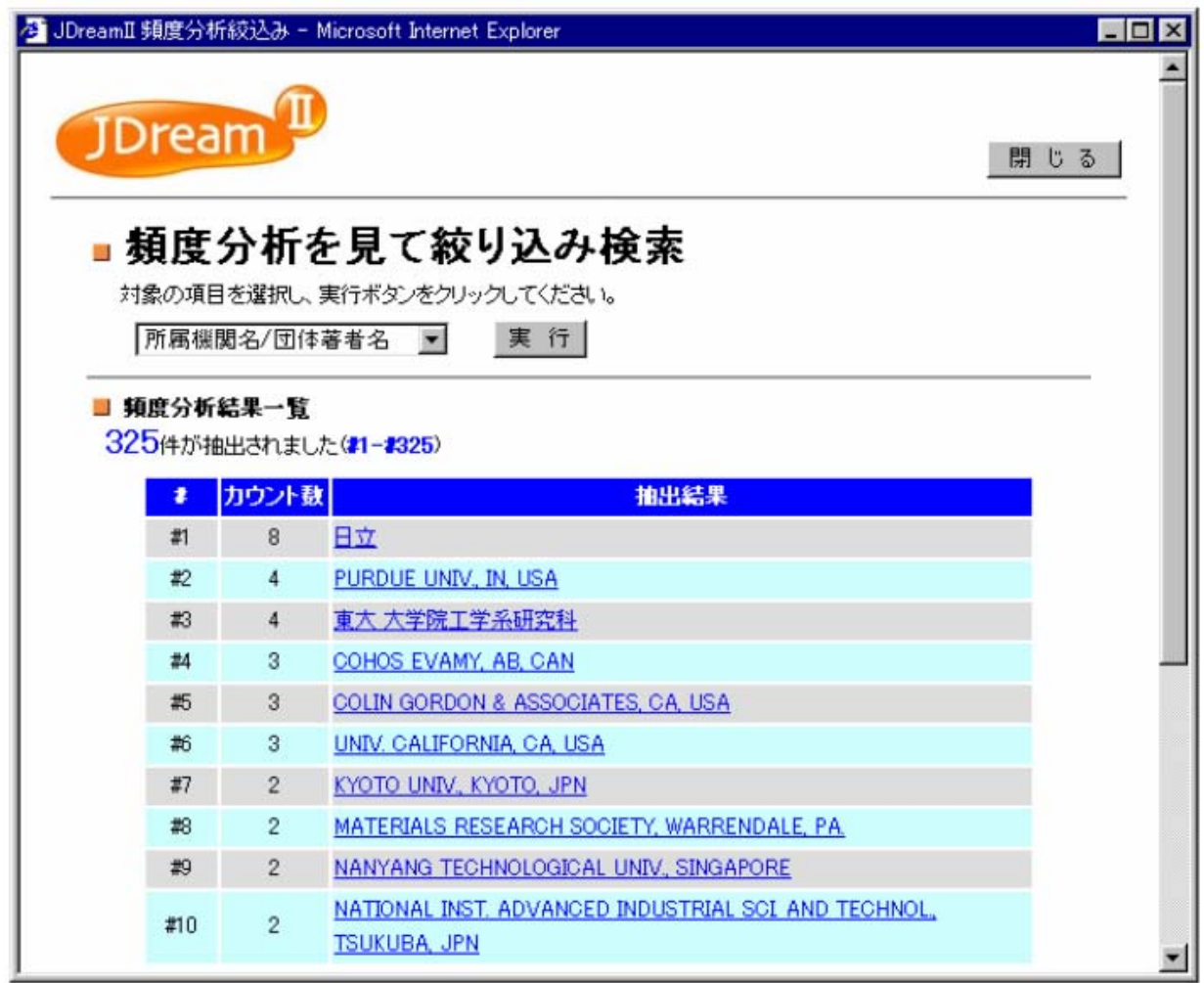

図7 頻度分析機能 